\title{
Dental students' perceptions of practice management and their career aspirations
}

\author{
S E van der Berg-Cloete, BChD, PGDip (Com Dent), MBA, DHSM; L Snyman, BChD, PGDip (Clin Dent), PGDip (Prac Man), PGCHE, MBL; \\ T C Postma, BChD, MChD (Com Dent), DHSM, PhD; J G White, BChD, BChD (Hons), Dipl Tertiary Education, MBA, PhD
}

Department of Dental Management Sciences, School of Dentistry, Faculty of Health Sciences, University of Pretoria, South Africa

Corresponding author: S E van der Berg-Clote (sophy.vanderberg-cloete@up.ac.za)

Background. The inclusion of 'management' competencies in medical curricula is widely propagated. There is some evidence in the literature that undergraduate dental students regard clinical skills as more important than management skills.

Objective. To investigate student perceptions regarding Dental Practice Management (DPM) as a subject in the undergraduate dental curriculum at the University of Pretoria, South Africa (SA) and to relate these perceptions to their future career aspirations.

Method. A cross-sectional survey was conducted in 2012 by means of an anonymous questionnaire among second-, third-, fourth- and fifth-year dental students $(N=228)$ at the University of Pretoria's School of Dentistry.

Results. Of the 192 respondents, 92\% ( $n=177)$ agreed that DPM should be a subject in an undergraduate curriculum, but there was no correlation with their career aspirations. Leadership and management skills (77.6\%), people skills (64.6\%), communication and listening skills (46.4\%) and personal style (42.2\%) were seen as the most important non-clinical skills. Students indicated their career aspirations as follows: private practice owners (45.3\%, $n=81)$, public sector and military $(15.1 \%, n=27)$, working abroad $(13.4 \%, n=24)$ and Medicross/Intercare $(11.2 \%, n=21)$. There were statistically significant differences $(p=0.001)$ among the study years with regard to private practice aspirations. Most students $(81.7 \%, n=156)$ indicated that they would specialise if afforded the opportunity.

Conclusion. In light of the prospects of the National Health Insurance (NHI) in SA, management and leadership skills will be vital to the successful longterm implementation of the NHI; hence, academic institutions and government should address these issues as a priority in their undergraduate curricula.

Afr J Health Professions Educ 2015;7(2):194-198. DOI:10.7196/AJHPE.408

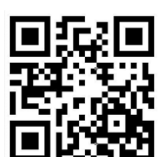

The inclusion of 'management' competencies in medical curricula is widely propagated. ${ }^{[1-3]}$ Partly based on this requirement, Dental Practice Management (DPM) is part of the undergraduate curriculum in the School of Dentistry, University of Pretoria, South Africa (SA). In recent years, DPM has been presented in the fourth and fifth years of study and can be considered a major study unit in the undergraduate dental curriculum. Teaching and learning in DPM typically include leadership, strategic management, financial management, personnel management, patient management, dentist-patient communication and marketing. ${ }^{[4]}$

To date, from a student perspective, no information is available regarding the need for DPM as a subject in undergraduate dental curricula in SA. There is, however, some evidence in the literature that undergraduate dental students do not regard the development of management skills to be as important as the attainment of clinical skills. ${ }^{[5]}$ DPM is likely to be relevant to those who aspire to become dental practice owners or managers in the private or public sector. It is debatable whether extensive teaching and learning in DPM will be perceived to be relevant by those who aspire to follow a career as employees only.

The literature shows that the majority of dental graduates in SA aspire to enter private practice. ${ }^{[6]}$ These trends may, however, be affected by the transformation in dental education during the past two decades. During this time, the profile of dental students changed from being male dominated to female dominated. ${ }^{[6]}$ Furthermore, social redress in correcting racial profiles at universities is actively being pursued ${ }^{[6]}$ It would therefore be valuable to investigate whether these demographic changes affect the career aspirations of dental students and if DPM is perceived to be relevant and necessary as a major subject in the undergraduate dental curriculum.

This study sought to investigate students' perceptions regarding the need for DPM as a subject in the undergraduate dental curriculum at the University of Pretoria and to relate these perceptions to their future career aspirations. The study also aimed to identify perceptions of the students regarding the most important skills (other than clinical skills) they have to learn in the undergraduate dental curriculum.

\section{Methods}

A cross-sectional survey was conducted in 2012 by means of an anonymous questionnaire among second-, third-, fourth- and fifth-year dental students $(N=228)$ at the University of Pretoria's School of Dentistry. The Research and Ethics Committees at the Faculty of Health Sciences, University of Pretoria approved the study protocol (91/2012).

\section{Sample}

Second-, third-, fourth- and fifth-year dental students $(N=228)$ at the University of Pretoria's School of Dentistry were invited to take part in the research.

\section{Questionnaire design}

In this pilot study a custom-designed questionnaire, in English, with open- and closed-ended questions, was administered to the various cohorts; participation was voluntary and anonymous. The questionnaire was not piloted before.

The researcher distributed the questionnaires to the students at the start of a routine lecture period (around midday). The students completed a consent 
form, which clearly stated that participation in the study was voluntary and that they could refuse to participate or discontinue at any time without giving a reason. The researchers collected the completed questionnaires immediately on completion.

Participants were asked to indicate their year of study, race and gender. They also had to specify whether they would wish to specialise if given an opportunity. Information on their previous exposure to public, military and private dental institutions was also elicited. Furthermore, students had to state their long-term career aspirations. They were asked whether they would prefer to work as an employee in the public sector, military, at Medicross/Intercare (managed healthcare provider) or for a private dentist. Alternatively, they could indicate whether they aspired to become a dental practice owner or business partner in a dental practice. An option was also provided to specify whether they wished to work abroad.

There was an open-ended question regarding the 'important skills other than clinical skills'; students had an option to indicate the four most important skills in terms of keywords. Their responses were thematically coded.

Students then had to respond to whether they thought that DPM should be a subject in an undergraduate dental curriculum. The questionnaire contained a Likert scale response choice of 'strongly disagree, 'sometimes disagree', 'disagree', 'sometimes agree' 'agree' or 'strongly agree' for the majority of the questions. An open-ended question where students were asked to write a reflection on why they thought DPM should/should not be a subject in an undergraduate dental curriculum, was also thematically coded.

\section{Data analysis}

The coded data were captured on an Excel spreadsheet and analysed using SPSS version 21. Descriptive statistics included determination of frequencies. The $\chi^{2}$ test was used for bivariate associations between demographic variables (year of study, sex, race) and students' perception of DPM as a subject in an undergraduate dental curriculum, their long-term career aspirations and their specialisation aspirations. A value of $p<0.05$ was considered statistically significant.

\section{Results}

Of the 228 targeted students, 192 (84\%) completed the questionnaire. The number of students per year of study varied between 39 and 59 .
Table 1 indicates that the respondents were mainly female (66.1\%, $n=127) ; 49.5 \%(n=95)$ were white, $33.0 \%(n=64)$ black, $11.5 \%(n=22)$ Asian, and $2.6 \%(n=5)$ coloured. The remaining $3.1 \%$ $(n=6)$ students did not indicate their race. The responses of students from Asian descent were similar to those of the white students. Similarly, the responses of the coloured students generally followed the trend of the black respondents. No further mention, therefore, is made in the results of the two minority groups of self-reported race.

The majority $(92 \%, n=177)$ of students agreed that DPM should be a subject in an undergraduate dental curriculum. Responses to an open-ended question where students had to write a reflection on why they thought DPM should/should not be a subject in an undergraduate dental curriculum, included: 'It is as important as clinical skills'; 'It will help to run a business/private practice'; 'It will assist us in knowing the external environment'; 'It prepares one for what to expect in the business world'; 'We as undergraduates may not see the importance now and may forget some information but one can see the role that it will play one day'.

Fig. 1 displays important skills other than clinical skills as perceived by the students. These include: ( $i)$ leadership and management skills (77.6\%), such as teamwork, motivation, time-management, financial management, business and decision-making skills; (ii) people skills (64.6\%), such as sympathy, caring, kindness, empathy, compassion and friendliness; and (iii) communication and listening skills (46.4\%), and personal style (42.2\%), such as thoroughness, tolerance, patience, positive attitude, enthusiasm and self-discipline. Skills pertaining to ethics and professionalism, and entrepreneurial skills were mentioned less often.
Less than half $(45.3 \%, n=81)$ of respondents (Table 2) indicated their aspirations to become private practice owners, i.e. $50 \%(n=31)$ males and $42.7 \%(n=50)$ females. At least $44(49.4 \%)$ of the white students indicated their intention to become private practice owners, while $39.7 \%(n=23)$ of black students indicated this option. These differences were not statistically significant.

Some respondents $(15.1 \%, n=27)$ (Table 2) mentioned that they intended to work in the public sector or the military. Furthermore, 29.3\% ( $n=17)$ of black students stated that they want to be employed in the public sector or in the military, while only $6.7 \%(n=6)$ of white respondents selected this option ( $\chi^{2}$ test, $\left.p<0.001\right)$. Twenty-one per

Table 1. Breakdown of students' gender, race and year of study

\begin{tabular}{lll}
\hline Variable & $\boldsymbol{n}$ & $\%$ \\
\hline Gender & 127 & 66.1 \\
Female & 65 & 33.8 \\
Male & & \\
Self-reported race & 64 & 33.3 \\
Black & 5 & 2.6 \\
Coloured & 22 & 11.5 \\
Asian & 95 & 49.5 \\
White & 6 & 3.1 \\
Not reported & & \\
Year of study & 43 & 22.4 \\
BChD II & 59 & 30.7 \\
BChD III & 39 & 20.3 \\
BChD IV & 51 & 26.6 \\
BChD V & 192 & \\
Total & &
\end{tabular}

Fig. 1. Students' perceptions of important non-clinical skills $(I T=$ information technology). 


\section{Research}

cent $(n=21)$ of male respondents compared with 12\% $(n=12)$ of female respondents were interested in working in the public sector or in the military. This difference was not statistically significant.

At least $13.4 \%(n=24)$ of the total respondents (Table 2) expressed an intention to work overseas. A larger proportion of white respondents $(14.6 \%, n=13)$ than black respondents $(5.2 \%, n=3)$, which included a higher ratio of males $(16.1 \%, n=10)$ than females $(12.0 \%, n=14)$, indicated their intent to work overseas (not statistically significant).
A further 11.2\% $(n=21)$ of respondents (Table 2) displayed an interest in working at Medicross/Intercare. The ratio of female respondents $(15 \%$, $n=17)$ interested in this option exceeded the ratio of male $(7 \%, n=4)$ respondents (not statistically significant). There was virtually no difference between the white $(11.2 \%, n=10)$ and black $(12.1 \%, n=7)$ students regarding the Medicross/Intercare option.

Table 2 further indicates that $8 \%$ of the respondents $(n=15)$ displayed an interest in working as an employee for a private dentist. White respondents

Table 2. Career aspirations of second- to fifth-year dental students

\begin{tabular}{|c|c|c|c|c|c|c|c|c|c|c|c|c|c|c|}
\hline \multirow{2}{*}{$\begin{array}{l}\text { Self-reported race } \\
\text { and gender }\end{array}$} & \multicolumn{2}{|c|}{$\begin{array}{c}\text { Public sector/ } \\
\text { military }\end{array}$} & \multicolumn{2}{|c|}{$\begin{array}{c}\text { Medicross/ } \\
\text { Intercare }\end{array}$} & \multicolumn{2}{|c|}{$\begin{array}{c}\text { Work as } \\
\text { employee for } \\
\text { private dentist } \\
\end{array}$} & \multicolumn{2}{|c|}{ Academic } & \multicolumn{2}{|c|}{$\begin{array}{c}\text { Private dental } \\
\text { practice owner }\end{array}$} & \multicolumn{2}{|c|}{ Overseas } & \multicolumn{2}{|c|}{$\begin{array}{c}\text { No career } \\
\text { option } \\
\text { indicated }\end{array}$} \\
\hline & $n$ & $\%$ & $n$ & $\%$ & $n$ & $\%$ & $n$ & $\%$ & $n$ & $\%$ & $n$ & $\%$ & $n$ & $\%$ \\
\hline $\begin{array}{l}\text { Black } \\
\text { (female) }\end{array}$ & 7 & 25.0 & 4 & 14.3 & 2 & 7.1 & 3 & 10.7 & 10 & 35.7 & 2 & 7.1 & & \\
\hline $\begin{array}{l}\text { Black } \\
\text { (male) }\end{array}$ & 10 & 33.3 & 3 & 10.0 & 1 & 3.3 & 2 & 6.7 & 13 & 43.3 & 1 & 3.3 & & \\
\hline $\begin{array}{l}\text { Black } \\
\text { (subtotal) }\end{array}$ & 17 & $29.3^{*}$ & 7 & 12.1 & 3 & $5.2^{\dagger}$ & 5 & 8.6 & 23 & 39.7 & 3 & 5.2 & & \\
\hline $\begin{array}{l}\text { Coloured } \\
\text { (female) }\end{array}$ & 1 & 25.0 & 1 & 25.0 & & & & & 2 & 50.0 & & & & \\
\hline $\begin{array}{l}\text { Coloured } \\
\text { (male) }\end{array}$ & 1 & 100.0 & 0 & 0.0 & & & & & 0 & 0.0 & & & & \\
\hline $\begin{array}{l}\text { Coloured } \\
\text { (subtotal) }\end{array}$ & 2 & 40.0 & 1 & 20.0 & & & & & 2 & 40.0 & & & & \\
\hline $\begin{array}{l}\text { Asian } \\
\text { (female) }\end{array}$ & 2 & 10.5 & 2 & 10.5 & & & 1 & 5.3 & 8 & 42.1 & 6 & 31.6 & & \\
\hline $\begin{array}{l}\text { Asian } \\
\text { (male) }\end{array}$ & 0 & 0.0 & 1 & 33.3 & & & 0 & 0.0 & 2 & 66.7 & 0 & 0.0 & & \\
\hline $\begin{array}{l}\text { Asian } \\
\text { (subtotal) }\end{array}$ & 2 & 9.1 & 3 & 13.6 & & & 1 & 4.5 & 10 & 45.5 & 6 & 27.3 & & \\
\hline $\begin{array}{l}\text { White } \\
\text { (female) }\end{array}$ & 4 & 6.5 & 10 & 16.1 & 12 & 19.4 & 3 & 4.8 & 28 & 45.2 & 5 & 8.1 & 0 & 0.0 \\
\hline $\begin{array}{l}\text { White } \\
\text { (male) }\end{array}$ & 2 & 7.4 & 0 & 0.0 & 0 & 0.0 & $13.5^{\dagger}$ & 0.0 & 16 & 59.3 & 8 & 29.6 & 1 & 3.7 \\
\hline $\begin{array}{l}\text { White } \\
\text { (subtotal) }\end{array}$ & 6 & $6.7^{\ddagger}$ & 10 & 11.2 & 12 & $13.5^{\dagger}$ & 3 & 3.4 & 44 & 49.4 & 13 & 14.6 & 1 & 1.1 \\
\hline $\begin{array}{l}\text { Race not reported } \\
\text { (female) }\end{array}$ & & & & & & & & & 2 & 50.0 & 1 & 25.0 & 1 & 25.0 \\
\hline $\begin{array}{l}\text { Race not reported } \\
\text { (male) }\end{array}$ & & & & & & & & & 0 & 0.0 & 1 & 100.0 & 0 & 0.0 \\
\hline $\begin{array}{l}\text { Race not reported } \\
\text { (subtotal) }\end{array}$ & & & & & & & & & 2 & 40.0 & 2 & 40.0 & 1 & 20.0 \\
\hline $\begin{array}{l}\text { Female } \\
\text { (subtotal) }\end{array}$ & 14 & 12.0 & 17 & 14.5 & 14 & $12.0^{\ddagger}$ & 7 & 6.0 & 50 & 42.7 & 14 & 12.0 & 1 & 0.9 \\
\hline $\begin{array}{l}\text { Male } \\
\text { (subtotal) }\end{array}$ & 13 & 21.0 & 4 & 6.5 & 1 & $1.6^{\ddagger}$ & 2 & 3.2 & 31 & 50.0 & 10 & 16.1 & 1 & 1.6 \\
\hline Total & 27 & 15.1 & 21 & 11.7 & 15 & 8.4 & 9 & 5.0 & 81 & 45.3 & 24 & 13.4 & 2 & 1.1 \\
\hline
\end{tabular}


$(13.5 \%, n=12)$ were more likely to indicate this option than black respondents $(5.2 \%, n=3)$ (Fisher exact test, $p<0.05$ ). Similarly, female respondents $(12 \%, n=7)$ were more inclined to select this option than males $(1.6 \%, n=1)$ (Fisher exact test, $p<0.05)$.

Of the total respondents, $5 \%(n=9)$ indicated an interest in becoming an academic, while $1.1 \%(n=2)$ did not indicate their future career aspirations (Table 2).

It should be noted that no statistically significant association could be found between the students' career aspirations and their perception about the need for DPM in the undergraduate dental curriculum.

Most students (81.7\%, $n=156)$ felt that they would specialise if they were afforded the opportunity.

Less than half $(43.2 \%, n=83)$ of the respondents had previous exposure to public or military service. Only $39.6 \%(n=76)$ had exposure to Medicross/Intercare, while the majority $(88.0 \%$, $n=169)$ had visited a private dental practice before. No statistically significant association could be shown between the students' previous experiences of private and public dental care facilities and their potential career choices.

\section{Discussion}

This study investigated the perceptions of dental students with regard to the need for DPM as a major study unit in an undergraduate dental curriculum.

The findings of the current study that the majority of dental students who responded to the questionnaire considered DPM to be a necessary field of study in the undergraduate dental curriculum at the University of Pretoria, correspond to similar research carried out abroad. The latter studies reported that students studying health sciences are indeed becoming increasingly aware of the need for business training. ${ }^{[7-9]}$ Qualified practising dentists also recognise the need for DPM education in the curriculum. ${ }^{[10]}$ The findings of the current study are, however, unique, as they provide the first indication of dental students' perceptions regarding the need for DPM in SA.

Clinical skills are generally considered extremely important, but 'soft' skills such as leadership, communication and DPM contribute to the success of practising health professionals. Its importance in an undergraduate curriculum has been acknowledged. ${ }^{[11-13]}$ The development of management skills is therefore becoming crucial for dentists to manage their practices successfully. ${ }^{[14-16]}$
These skills are often neglected in undergraduate curricula despite tendencies that students recognise them as crucial. ${ }^{[17-20]}$ In our study, students were asked to indicate the most important skills - other than clinical skills. From their responses it could be deducted that leadership and management were considered to be the most important skills to acquire other than clinical skills. This study is the first to point out that dental students regard leadership and management as priority skills.

The students' perception that DPM should be part of the dental curriculum at the University of Pretoria is probably the result of their awareness of the complexity of the dental practice 'business' environment and changes facing dentists in the external environment. ${ }^{[2]]}$ These features are actively addressed in the undergraduate dental curriculum from the second year of study onwards as part of the Integrated Dentistry module (second year of study) and Comprehensive Patient Management (CPM) module (third to fifth year of study) (CPM study guide - available from the authors).

Another possible reason for the overwhelming response that DPM should be a subject in the undergraduate dental curriculum may reflect the students' career aspirations. No associations could, however, be found between the career aspirations of the students and their opinion about the need for DPM as a subject, also not when analysed in terms of the year of study. A few local and international studies have suggested that the majority of students opt for private practice rather than the public sector. ${ }^{[6,22-25]}$ About $45.3 \%$ of the students indicated a vision of owning a private dental practice, with only $15.1 \%$ showing a desire to work in public health facilities or in the military. These findings are not surprising, as it is well known that government and the military have a fixed number of posts and many of the governmental posts in SA are annually filled by dentists in community service. Private dental practice is, therefore, the most viable part of the market for a qualified dentist for employment in SA. The potential future strengthening of the public sector by means of the National Health Insurance (NHI) may, however, change these perceptions. In a study done in the UK, where there is a well-established National Health Service (NHS) with ample employment opportunities, a high ratio of students indicated an intention to work in the NHS. ${ }^{[26]}$ Another interesting finding of the current study is the much higher ratio of black students who indicated an interest to work in the public sector or the military compared with white students.
The findings illustrate that, compared with males, female students (especially white females) who do not aspire to become private practice owners want to become employees in a private dental practice or work at institutions such as Medicross or Intercare. These trends are important to monitor in future as female dental students are in the majority.

The abovementioned findings are indicative of differences that may exist among dental students with regard to career aspirations. This is important in SA, where political redress is continuously taking place. In the current study, white students are $\sim 50 \%$ of the study sample, which is not reflective of the demographic profile of the country. The racial profile at the University of Pretoria is however normalising over time, i.e. a higher ratio of black students will graduate in future. The study showed significant differences between the career aspirations of white and black students. It is important for tertiary institutions to be aware of the changing career aspirations of the emerging oral healthcare workforce, as this will assist in future planning and policy decisions in terms of the content of dental curricula. The current study provides valuable local data in this regard.

The results also highlighted that the majority of the dental students at the University of Pretoria would specialise if they were afforded the opportunity. Conflicting evidence in this regard is available in the literature. Freire et al., ${ }^{[22]}$ Grytten and Skau ${ }^{[27]}$ and Rashid et al. ${ }^{[28]}$ showed that the majority of students wish to specialise, while Marino et al. ${ }^{[23]}$ and Drinkwater et al. ${ }^{[29]}$ indicated that the majority of students wanted to be general dentists only. Male students were more likely to specialise, while females preferred to pursue an academic career.

The findings also suggest that only a small percentage of local dental students are interested to employ their skills abroad. The relatively low percentage probably results from South Africans having to pass an examination abroad (since 2000). It has become increasingly difficult for SA dentists to be employed in countries such as the UK. ${ }^{[30]}$

\section{Conclusion}

The two main findings of this study are as follows:

- Second- to fifth-year dental students are of the opinion that DPM is an important part of the dental curriculum at the University of Pretoria and regard leadership and management skills as being as important as clinical skills. 
- Sociodemographic differences exist in the career aspirations of dental students, which is important to take into account given the changing demographic profile of dental students.

The greatest limitation of the current study is that the results are merely a snapshot of students' perceptions at a single university in SA at a given point in time. The results can therefore not summarily be generalised with regard to other training institutions. This research should, however, be expanded to a national level, incorporating all the dental training institutions through a collaborative effort to investigate the need for management and leadership training. The questionnaire used in this pilot study appears to have rendered reliable results and can serve as the basis for future research. The opinions of academics and dentists from both the public and private sectors should also be sourced in future research projects.

Acknowledgements. The researchers acknowledge the positive attitudes and cooperation and inputs of the participating students. We thank Barbara English, Research Office, Faculty of Health Sciences, University of Pretoria for her editing skills.

\section{References}

1. Frenk J, Chen L, Bhutta ZA, et al. Health professionals for a new century: Transforming education to strengthen health systems in an interdependent world. Revista Peruana de Medicina Experimental Salud Pública 2011;28(2):337-341.

2. Freeman M, Miller C, Ross N. The impact of individual philosophies of teamwork on multi-professional practice and the implications for education. Journal of Interprofessional Care 2000;14(3):237-247.

3. Frank JR, Danoff D. The CanMEDS initiative: Implementing an outcomes-based framework of physician competencies. Med Teach 2007;29:642-647. [http://dx.doi.org/10.1080/01421590701746983]

4. University of Pretoria Comprehensive Patient Management (TBW370-570) Study Guide. Pretoria: University of Pretoria, 2012.

5. Cardall WR, Rowan RC, Bay C. Dental education from the students' perspective: Curriculum and climate. J Dent Educ 2008;72(5):600-609.

6. Lalloo R, Ayo-Yusuf OA, Yengopal V. Early-phase dental students' motivations and expectations concerning the 6. Lalloo R, Ayo-Yusuf OA, Yengopal V. Early-phase dental students'
study and profession of dentistry. S Afr Dent J 2008;63(4):216-220.

7. Barber M, Wiesen R, Arnold S, Taichman RS, Taichman LS. Perceptions of business skill development by graduates of the University of Michigan dental school. J Dent Educ 2011;75(4):505-517.
8. Busari JO, Berkenbosch L, Brouns JW. Physicians as managers of health care delivery and the implications for postgraduate medical training: A literature review. Teach Learn Med 2011;23(2):186-196. [http://dx.doi.org/10. $1080 / 10401334.2011 .561760$

9. Jaarsma DA, Dolmans DH, Scherpbier AJ, van Beukelen P. Preparation for practice by veterinary school: A comparison of the perceptions of alumni from a traditional and an innovative veterinary curriculum. J Vet Med Educ 2008;35(3):431-438. [http://dx.doi.org/10.3138/jvme.35.3.431]

10. Khami MR, Akhgari E, Moscowchi A, et al. Knowledge and attitude of a group of dentists towards the topics of a course on principles of successful dental practice management. J Dent Med 2012;25(1).

11. Hobson RS. Challenges to future dental education. Br Dent J 2009;206(3):125-126. [http://dx.doi.org/10.1038/ sj.bdj.2009.54]

12. Jawale BA, Bendgude V, Husain N, Thosar N, Tandon P. Soft skill appraisal for dentistry: A tool for positive practice management. J Contem Dent Pract 2011;12(6):475-478.

13. Practice management. J Contem Dent Pract 2011;12(6):475-478. European dental schools: Part I. Eur J Dent Educ 2006;10(3):123-130.

14. Bajaj A. Good management underpins good clinical dentistry. Vital 2010;7(4):16-18.

15. Dunning DG, Lange BM, Madden RD, Tacha KK. Prerequisites in behavioural science and busines: Opportunities for dental education. J Dent Educ 2011;75(1):77-81

6. Willis DO. Using competencies to improve dental practice management education. J Dent Educ 2009;73(10):1144-1152

17. Abbas MR, Quince TA, Wood DF, Benson JA. Attitudes of medical students to medical leadership an management: A systematic review to inform curriculum development. BMC Med Educ 2011;11(93):1-21. [http:// dx.doi.org/10.1186/1472-6920-11-93]

18. Kalenderian $\mathrm{E}$, Timothé $\mathrm{P}$. Integrating leadership into a practice management curriculum for dental students. Dent Educ 2010;74(5):464-471.

19. Lennon MA, Ireland RS, Tappin J, et al. The personal dental service as a setting for an undergraduate clinical programme. Br Dent J 2004;196(7):419-422.

20. Slavkin HC, Lawrence L. Incorporating leadership knowledge and skills into the dental education community. J Dent Educ 2007;71(6):708-712.

21. White JG. Interacting forces influencing private dental practice in South Africa: Implications for dental education. S Afr Dent J 2008;63(2):80-85.

22. Freire MCM, Jordao LMR, de Paula Ferreira N, de Fatima Nunes M, Queiroz MG, Leles CR. Motivation toward career choice of Brazilian freshman students in a fifteen-year period. J Dent Educ 2011;75(1):115-121.

23. Mariño R, Au-Yeung W, Habibi E, Morgan M. Sociodemographic profile and career decisions of Australian oral health profession students. J Dent Educ 2012;76(9):1241-1249.

4. Scarbecz M, Ross JA. The relationship between gender and postgraduate aspirations among first- and fourth-yea students at public dental schools: A longitudinal analysis. J Dent Educ 2007;71(6):797-809.

25. Stewart F, Drummond J, Carson L, Theaker E. Senior dental students' career intentions, work-life balance an retirement plans. Br Dent J 2007;203(5):257-263.

26. Gallagher JE, Patel R, Wilson NHF. The emerging dental workforce: Long-term career expectations and influences. A quantitative study of final year dental students' views on their long-term career from one London Dental School. BMC Oral Health 2009;9(35):1-9.

27. Grytten J, Skau I. Specialization and competition in dental health services. Health Economics 2009;18(4):457-466.

28. Rashid HH, Ghotane SG, Abufanas SH, Gallagher JE. Short and long-term career plans of final year dental students in the United Arab Emirates. BMC Oral Health 2013;13(1):1-9.

29. Drinkwater J, Tully MP, Dornan T. The effect of gender on medical students' aspirations: A qualitative study. Med Drinkwater J, Tully MP, Dornan T. The effect of gender on medical students' aspir

30. Eaton K, Balázs P. Dentists' migration to and from Hungary between 1970 and 2005 and into the United Kingdom between 1994 and 2005. Oral Health and Dental Management in the Black Sea Countries 2008:7(4):3-11 